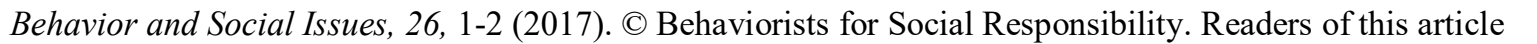
may copy it without the copyright owner's permission, if the author and publisher are acknowledged in the copy

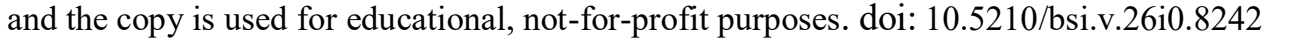

\title{
EDITORIAL: STANDING FOR SCIENCE IS STANDING FOR JUSTICE
}

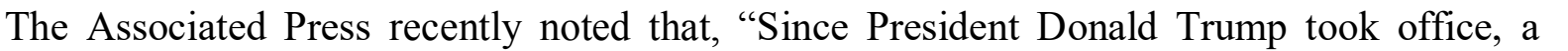

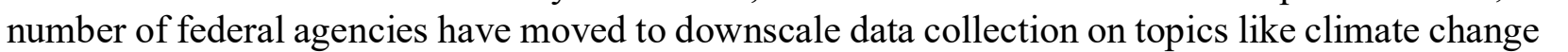

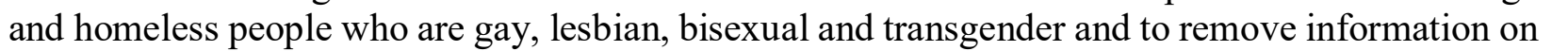

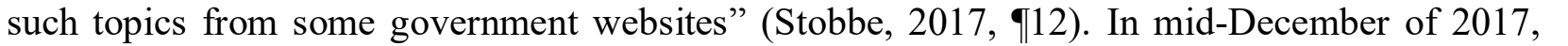

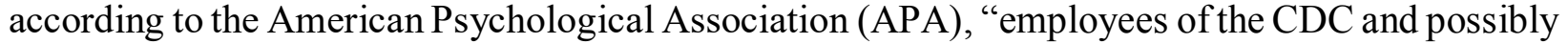

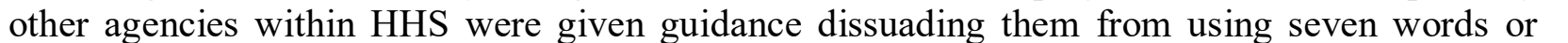

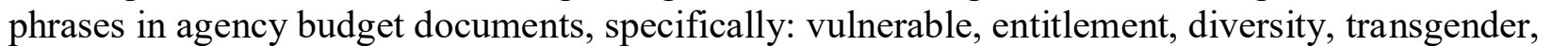

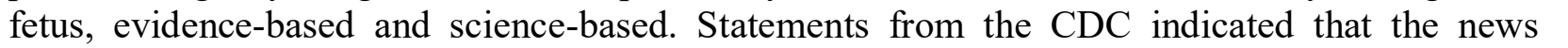

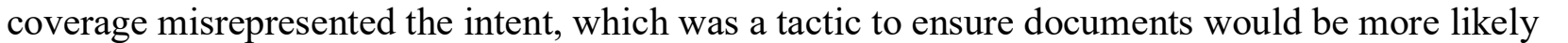

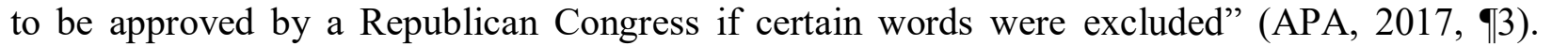

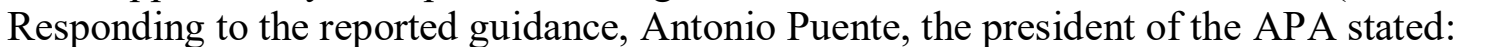

Restricting these key words follows this administration's disturbing pattern of devaluing

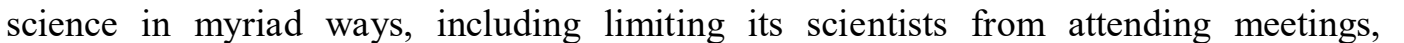

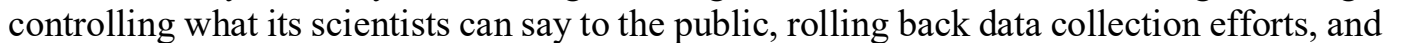

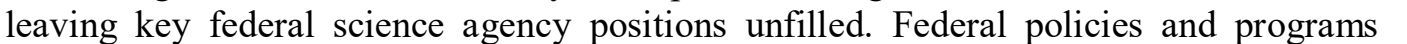

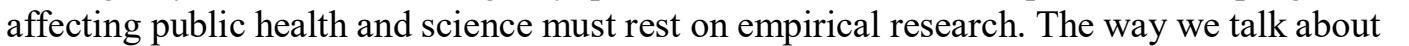
ए

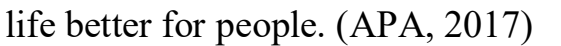

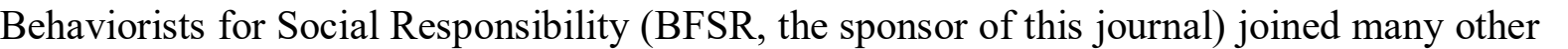
scientific and service organization in expressing deep concern, not only about the "censorship"

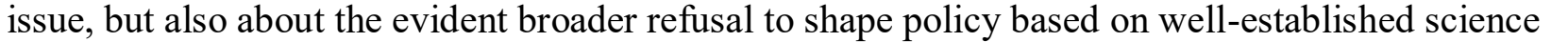
प

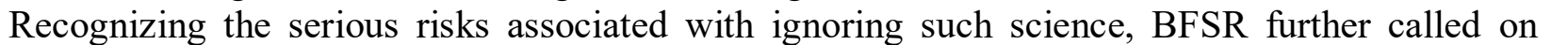

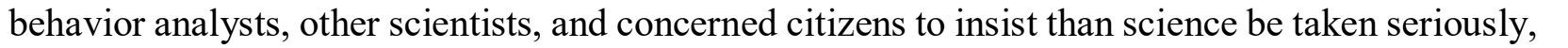

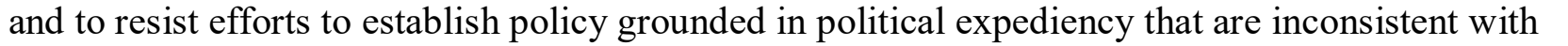

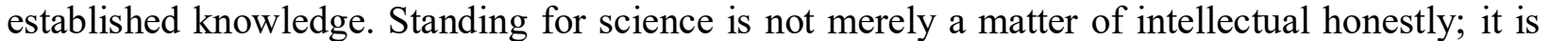

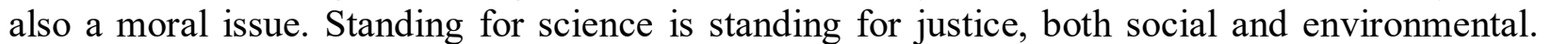

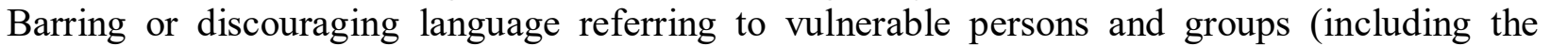
specifically targeted trans* population") offers clear, though camouflaged and deniable, guidance

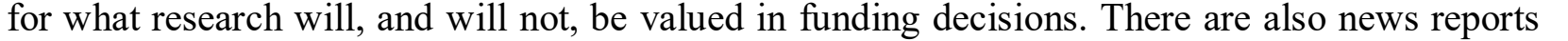
that CDC staff were directed not to use the phrase "health equity" in presentations or public talks-

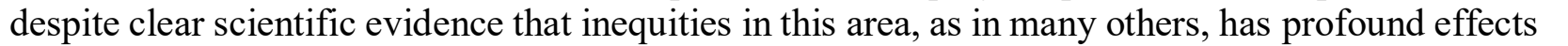

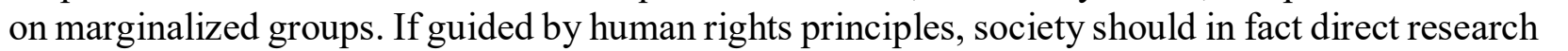

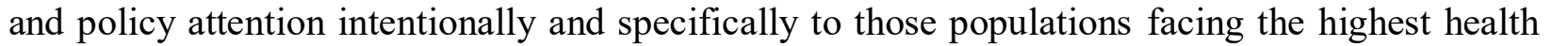

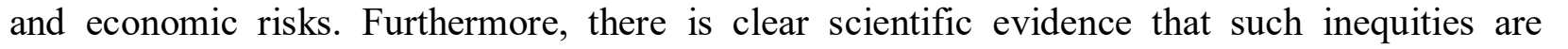

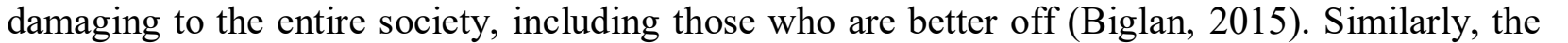

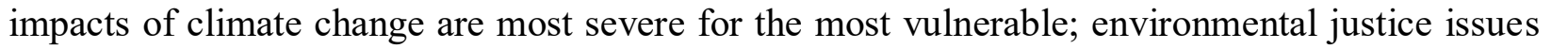

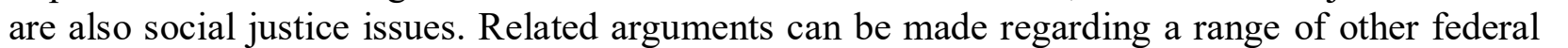

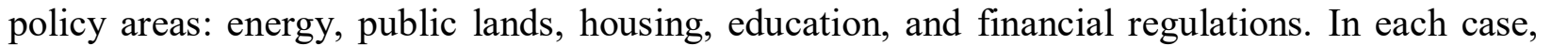




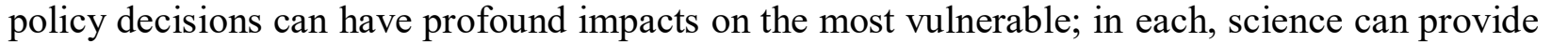

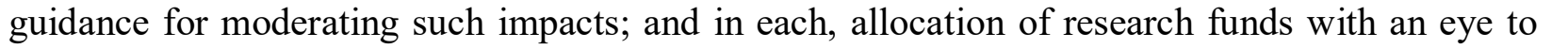

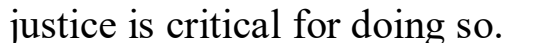

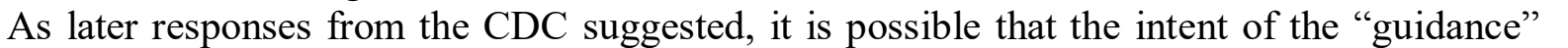

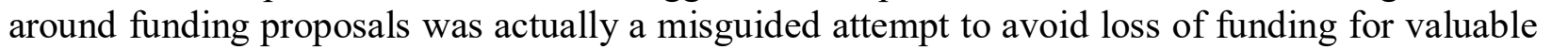

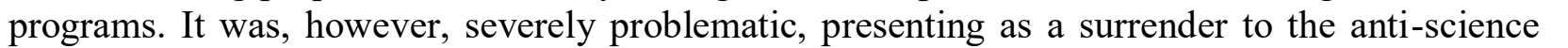

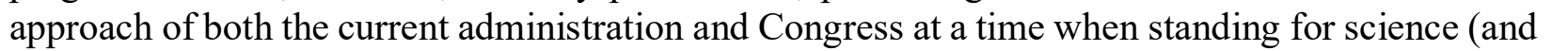
ए

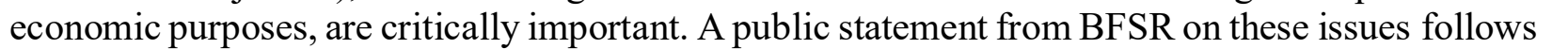

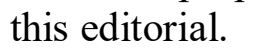

西

\section{University of Illinois at Chicago}

\section{References}

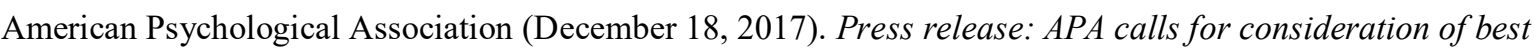

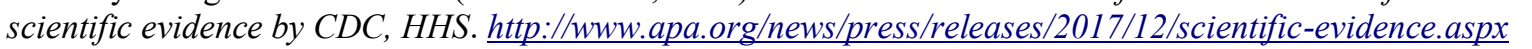

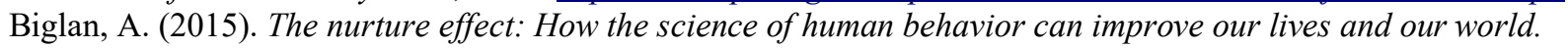

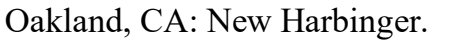

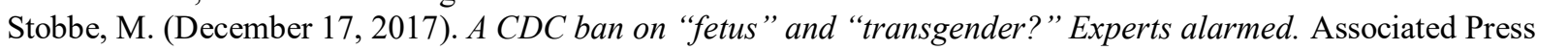

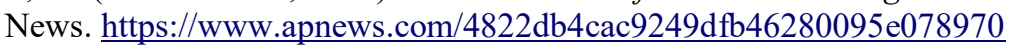

